\title{
A pilot of a school-based dental treatment programme for vulnerable children with possible dental neglect: the Back2School programme
}

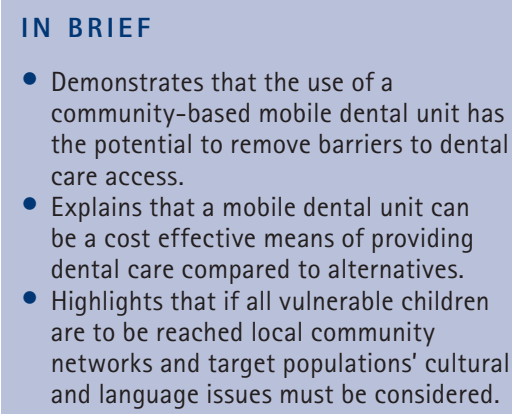

\author{
D. Simons, ${ }^{* 1}$ N. Pearson ${ }^{2}$ and P. Evans ${ }^{3}$
}

\begin{abstract}
Background The general dental practitioners and community dental services of Barts Health NHS Trust in City and Hackney and Tower Hamlets PCTs in East London currently provide a school-based oral health prevention programme. The programme provides dental screening for three- to six-year-olds, fluoride varnish application twice during the school year and engaging with the families to encourage dental attendance. An evaluation of the programme suggested that children with a dental treatment need, identified by the screening, were not being taken for further dental care. Objective The aim of this 'Back2School' pilot was to evaluate the use of mobile dental units in the provision of care to this group of children. The objectives were to assess if this care was acceptable to the children and their families, to evaluate dental treatment provided, patient attendance, costs of the service and whether it would be a viable method to provide dental care. Methods The rotation of the mobile dental unit in this pilot offered ten sessions of dental care over five days in three different locations. The locations were chosen near the five schools covered by the community dental service. Results A total of 63 children were seen; 33 females and 30 males, which included 7 walk-in patients. Five children had extractions and the number of fillings ranged from one to six. Of the 63 children seen only 8 (13\%) had attended a dentist before, 59 (93\%) of the children were rated 'high risk' for dental disease, 61 (97\%) of the children received a fluoride varnish application and 95.2 UDAs were achieved. Feedback was positive overall. Conclusions The use of a communitybased mobile dental unit has the potential to be a cost-effective method to remove barriers to dental care access, both for the treatment of vulnerable children and as a first point of contact in the dental care pathway.
\end{abstract}

\section{INTRODUCTION}

There is much debate in the UK concerning how best to manage the dental care of children with carious primary teeth. Many parents do not see that restoration of asymptomatic carious primary teeth as imperative $^{1}$ and so although dental caries is a preventable disease it is a persistent public health problem. Dental caries has been shown to be associated with social deprivation, with large geographical and social inequalities across the UK and it is understood that these oral health inequalities are not successfully tackled

\footnotetext{
${ }^{1}$ Assistant Clinical Director, ${ }^{2}$ Clinical Director, ${ }^{3}$ Senior Dental Officer, Barts Health NHS Trust, Community Dental Services, 3rd floor Block B, St Leonard's Primary Care Centre, Nuttall Street, London, N1 5LZ

${ }^{*}$ Correspondence to: Debra Simons

Email: Debra.Simons@bartshealth.nhs.uk
}

\section{Online article number E15}

Refereed Paper - accepted 10 July 2013

DOI: 10.1038/sj.bdj.2013.998

${ }^{\circledR}$ British Dental Journal 2013; 215: E15 by treatment services. There is no evidence that increasing the provision of dental care decreases inequity in oral health; the cost/ benefit ratio of this approach has been described as poor, that the cost of services to reduce tooth loss in disadvantaged groups by one tooth per person is unacceptably high and funds would be better used on public preventive approaches. ${ }^{2}$ However, untreated dental caries can significantly impact on the quality of life of children and their dietary intake. ${ }^{3}$ Children with untreated tooth decay had significantly poorer oral health-related quality of life than children without decay as assessed both by the children and their parents. The consequences of high caries levels also include a higher risk of hospitalisations and emergency dental visits, increased days with restricted activity and absence from school. Dental pain has an impact on the child's educational development ${ }^{3}$ and interference with playing and socialisation. ${ }^{4}$
The American Academy of Paediatric Dentistry defined parents' failure to pursue the necessary dental treatment required to maintain the child's oral health and to ensure their freedom from pain and infection as dental neglect (DN). ${ }^{5}$ The NICE guideline recognised two aspects of DN: the parent's persistent failure to obtain NHS treatment for their child's dental caries when such NHS dental services were available, and the possibility of child maltreatment due to an absent or unjustifiable explanation for a child's oral injury. ${ }^{6}$

Research has identified barriers for children from low socioeconomic status families to accessing dental services. ${ }^{7-10}$ These include limited access to transportation, lack of information, language and cultural barriers; with proposals for reducing these including a need to extend services through outreach activity, develop communication skills within dental care and liaise with other health services. ${ }^{11}$ A review investigating the 
effectiveness of different approaches for increasing dental attendance by families from deprived areas in the $\mathrm{UK}^{12}$ concluded that the best two approaches were the mobile dental unit (MDU) at school premises and the dental access centre. Both responded to the attendance preferences of the populations served, however, the best ways to address the unmet treatment need of children and families in lower socioeconomic groups still needs further investigation. ${ }^{12}$ Families are the key determinant of positive outcomes for their children. Lower levels of parental engagement are more common in families experiencing higher levels of deprivation. It is particularly during a child's early years that parental engagement is most effective in securing better outcomes for their children in later life. There is a need to develop strategies that work with whole families. ${ }^{13}$

The level of dental disease among young children in Tower Hamlets (TH) is high with $39 \%$ of five-year-old children experiencing tooth decay; compared to 33\% for London and 31\% for England ${ }^{14}$ and dental attendance by children in $\mathrm{TH}$ is well below the London average of $67 \%$ with only 54\% accessing general dental practice (GDP). TH has both one of the youngest populations in the country, 54,300 people are 19 or younger, and the highest level of child poverty in the country (48\%), with the highest free school meals entitlement in the UK (52\% of children). ${ }^{15}$ Children who live in poverty experience disadvantage in many aspects of their life, and are more likely to suffer poor health and reach a lower level of educational attainment.

To address the high levels of disease and low levels of attendance a preventive oral health programme was introduced in TH and City and Hackney schools with a number of qualitative interventions with families. The programme provides dental screening for three- to six-year-olds, fluoride varnish application twice during the school year and engaging with the families to encourage dental attendance. An evaluation of this oral health programme suggested that children with a treatment need, identified by the screening, were not being taken for further dental care. The aim of this 'Back2School' pilot was to evaluate the use of the MDU in the provision of care to this vulnerable group of children. The objectives were to assess if this care was acceptable to the children

\section{Table 1 Five CDS TH schools matched to five GDP TH schools}

\begin{tabular}{l|l|l} 
School & No. of children screened & $\begin{array}{l}\text { No. of children with UTN at the second fluoride } \\
\text { application }(\%)\end{array}$ \\
\hline CDS1 & 75 & $9(12 \%)$ \\
\hline GDP1 & 71 & $9(13 \%)$ \\
\hline CDS2 & 65 & $19(29 \%)$ \\
\hline GDP2 & 81 & $22(27 \%)$ \\
\hline CDS3 & 98 & $10(10 \%)$ \\
\hline GDP3 & 139 & $18(13 \%)$ \\
\hline CDS4 & 141 & $22(16 \%)$ \\
\hline GDP4 & 99 & $17(17 \%)$ \\
\hline CDS5 & 201 & $28(14 \%)$ \\
\hline GDP5 & 183 & $26(14 \%)$
\end{tabular}

\section{Table 2 Access data for five TH CDS schools}

\begin{tabular}{l|l|l|l} 
School & $\begin{array}{l}\text { Target number of } \\
\text { children in school }\end{array}$ & $\begin{array}{l}\text { Children booked from } \\
\text { the school }(\%)\end{array}$ & $\begin{array}{l}\text { Number of children that attended } \\
\text { appointment from that school (\%) }\end{array}$ \\
\hline CDS1 & 9 & $9(100 \%)$ & 7 \\
\hline CDS2 & 19 & $17(89 \%)$ & 13 \\
\hline CDS3 & 10 & $5(50 \%)$ & 4 \\
\hline CDS4 & 22 & $10(45 \%)$ & 6 \\
\hline CDS5 & 28 & $9(32 \%)$ & 8 \\
\hline TOTAL & 88 & $50(57 \%)$ & $38(43 \%)$
\end{tabular}

\begin{tabular}{|l|l|l|}
\multicolumn{3}{|l}{ Table 3 Access data for five GDP TH schools } \\
\hline School & $\begin{array}{l}\text { Target number of children } \\
\text { in school }\end{array}$ & $\begin{array}{l}\text { Total children registered with GDP from } \\
\text { NHSBSA data }\end{array}$ \\
\hline GDP1 & 9 & 1 \\
\hline GDP2 & 22 & 1 \\
\hline GDP3 & 18 & 6 \\
\hline GDP4 & 17 & 4 \\
\hline GDP5 & 26 & 10 \\
\hline TOTAL & 92 & $22(24 \%)$ \\
\hline
\end{tabular}

and their families, to evaluate dental treatment provided, patient attendance, costs of the service and whether it would be a viable method to address DN.

\section{METHOD}

In the majority of schools in $\mathrm{TH}$ the fluoride varnish programme has been provided by GDPs, only five schools were covered by the Community Dental Service (CDS), but during 2011-2012, ten schools previously managed by a GDP were allocated to the CDS. The children, aged between three and six years old, and their families had been given letters on their oral treatment needs at both fluoride applications. The ten schools previously covered by the GDP had established links to that practice and the children in these ten schools were encouraged to attend there for dental care. The five schools with only links to the CDS were given information on local GDPs and how to access care. It was apparent at the second applications, which were six months after the first, that many children in all the schools had still not obtained dental care and had an 'urgent' treatment need (UTN): defined as 'a molar tooth with active caries into dentine, abscess or sinus'. According 


\begin{tabular}{|c|c|c|c|}
\hline Question & Yes & No & $\begin{array}{l}\text { Don't } \\
\text { know }\end{array}$ \\
\hline Were you happy with the treatment your child/children received? & $12(92 \%)$ & $1(8 \%)$ & \\
\hline Did the dentist explain the reason for any treatments or actions? & $10(77 \%)$ & $3(23 \%)$ & \\
\hline Was the location of the dental mobile convenient for you? & $12(92 \%)$ & $1(8 \%)$ & \\
\hline $\begin{array}{l}\text { Now that your child/children have had treatment in the mobile, do you feel } \\
\text { you are more likely to visit a dental practice to have regular treatment? }\end{array}$ & $11(85 \%)$ & $1(8 \%)$ & $1(8 \%)$ \\
\hline
\end{tabular}

\begin{tabular}{|c|c|c|c|c|c|}
\hline Question & $\begin{array}{l}\text { Very } \\
\text { good (5) }\end{array}$ & (4) & $\begin{array}{l}\text { Neither } \\
\text { (3) }\end{array}$ & (2) & $\begin{array}{l}\text { Very } \\
\text { poor (1) }\end{array}$ \\
\hline $\begin{array}{l}\text { How helpful were staff with any concerns or } \\
\text { questions you had about your treatment or care? }\end{array}$ & $10(77 \%)$ & 0 & $3(23 \%)$ & 0 & 0 \\
\hline $\begin{array}{l}\text { How would you rate the care or treatment your } \\
\text { child/children received? }\end{array}$ & $10(77 \%)$ & $2(15 \%)$ & $1(8 \%)$ & 0 & 0 \\
\hline $\begin{array}{l}\text { 'I felt that my child and I were treated with } \\
\text { dignity and respect' }\end{array}$ & $11(85 \%)$ & $2(15 \%)$ & 0 & 0 & 0 \\
\hline
\end{tabular}

Table 6 Questionnaire results: 'Your visit to the dental mobile' open questions

\begin{tabular}{l|l|l|}
$\begin{array}{l}\text { What did you or your children like best about } \\
\text { the dental mobile service? } \\
\text { (more than one answer) }\end{array}$ & Dentist was very nice & $9(69 \%)$ \\
& Friendly & $1(8 \%)$ \\
& Stickers and gift & $9(69 \%)$ \\
& Enjoyed the whole experience & $1(8 \%)$ \\
& Nothing in particular & $3(23 \%)$ \\
& The chair & $3(23 \%)$ \\
\hline $\begin{array}{l}\text { What could we do to improve our dental } \\
\text { mobile service? }\end{array}$ & Keep up the good work, excellent & \\
& service, everything was good & $10(77 \%)$ \\
& Can't think of anything & $2(15 \%)$ \\
& Appointments too rushed & $1(8 \%)$ \\
& More sessions & $3(23 \%)$
\end{tabular}

to $\mathrm{NICE}^{6}$ these children could be defined as suffering DN, so at the end of July 2012, the children $(\mathrm{n}=88)$ from the five CDS schools, which had no established GDP links, were again contacted by the CDS outreach team to encourage uptake of care. The conversation with the families was conducted by telephone using a standard script format. The objective was to ascertain from the families/carers if they had obtained dental care for their child, to offer oral health advice, link the families to local GDPs or alternatively, if barriers were identified, an appointment was offered to provide the dental care from conveniently sited MDU during the school holidays. As a result of these conversations and to encourage attendance, dental care was also offered to siblings of the children.

The rotation of the MDU in this pilot offered ten sessions of dental care over five days in three different locations. The locations were chosen near the five CDS schools and all sites risk assessed for ease of access, safety and high visibility. The service was planned in cooperation with local stakeholders, children centres and community centres. All appointments were made by telephone; families were phoned and reminded both the day before and on the day of the appointment. Parents/carers were told about the treatment their child required and were given the opportunity to discuss this fully with the dentist. The treatment plan was agreed in full and signed by the parent/carer at the appointment. If the treatment was unable to be finished at that time, further appointments were made at the families' convenience. All treatment was carried out only following completion of a full medical history. Every MDU was staffed by a dentist, dental nurse and an outreach worker.

To aid evaluation, five of the schools that were previously allocated to the GDP and had links to that practice were matched to the five CDS schools by postcode, size and numbers of children (Table 1). Families had consented to information sharing between schools and healthcare professionals, so anonymised dental registration (NHSBSA data) of the children from the five GDP's schools was used as a comparison to evaluate the MDU uptake by the families.

\section{DATA COLLECTION}

Anonymised data and information were collected from patient's records. The data review was undertaken as an audit of the MDU cost effectiveness and for reporting mechanisms to the commissioning PCT on the programme. Research ethics approval was not sought; however, the Declaration of Helsinki, in relation to research ethics and data protection protocols, was adhered to. All data were anonymised and abstracted directly onto a passwordprotected computer. Qualitative feedback and patient related outcome measures were obtained from structured conversations with $20 \%$ of the families at the appointment and via follow-up phone calls conducted after completion of the pilot and this was anonymised before analysis.

\section{RESULTS}

Telephone contact was attempted with all 88 families; 13 (15\%) families were unable to be contacted, 5 (6\%) parents/carers said they had taken their child to a GDP, 7 (8\%) said they would take their child to a GDP once the treatment needs of their child were explained to them and locations of GDPs discussed, and 13 (15\%) parents/carers did not want to discuss their child's dental care with the team or make any arrangements for this care. Seventy-two appointments were booked, of which 50 (57\%) were given to the target 88 children and 22 to siblings. Thirty-eight of the target children attended (43\%) while 12 of the target children failed their appointments (Table 2) despite reminders and telephone conversations. A total of 63 children were seen; 33 females and 30 males, which included 7 walk-in patients, as vacant appointment slots were filled by children that had not attended a dentist before and approached the MDU while it was parked with the parent/carer who requested care for their child. Two children needed referral for general anaesthesia extractions and ten were referred internally within the CDS for further treatment under inhalation sedation. One child had already had general 
anaesthetic extractions. From the completed treatments (51 children), five children had extractions and the number of fillings ranged from one to six. Of the 63 children seen only $8(13 \%)$ had attended a dentist before, 59 (93\%) of the children were rated 'high risk' for dental disease, 61 (97\%) of the children received a fluoride varnish application and 95.2 UDAs were achieved. The NHSBSA data for the five matched TH schools that were previously managed by the GDP can be seen in Table 3, which showed that $22(24 \%)$ of the children registered with a GDP.

The two evaluation questions asked at the appointment related to the impact of oral diseases on their child's well-being. Q1: 'Has (child name) general health been affected by problems with his/her teeth, gums or mouth?' on a scale of one (not at all) to five (constantly). Q2: 'In the last four weeks how would you rate the health of (child name) mouth?' from five (very poor) to one (very good), with the impact score for the sample being 3.85 and 3.07 respectively. Four weeks after treatment the families were contacted by telephone to ascertain their feedback on the service (Tables 4-6) with Questions 1 and 2 being repeated, the impact of Q1 was 3.69 and Q2 was 1.92 (Fig. 1).

\section{DISCUSSION}

The aim of this 'Back2School' pilot programme was to evaluate the use of the MDU in the provision of oral care to a vulnerable group of children as an adjunct to a fluoride application programme. Although not all families could be contacted, $43 \%$ of the target children obtained care. This was almost twice the percentage of children that registered with a GDP practice (22\%) from the five matched TH schools. We are aware that although the postcodes of the schools were matched, the children's home postcodes were not and although from ethnicity data the schools appeared to serve the same community, without analysis of home postcodes the five matched schools cannot be a true control. There were an extra seven children who accessed care who had not been to a dentist before and came simply because the MDU was on their doorstep. Contacting the families by telephone or face-to-face contact appeared crucial in getting them to access care. All the families had received

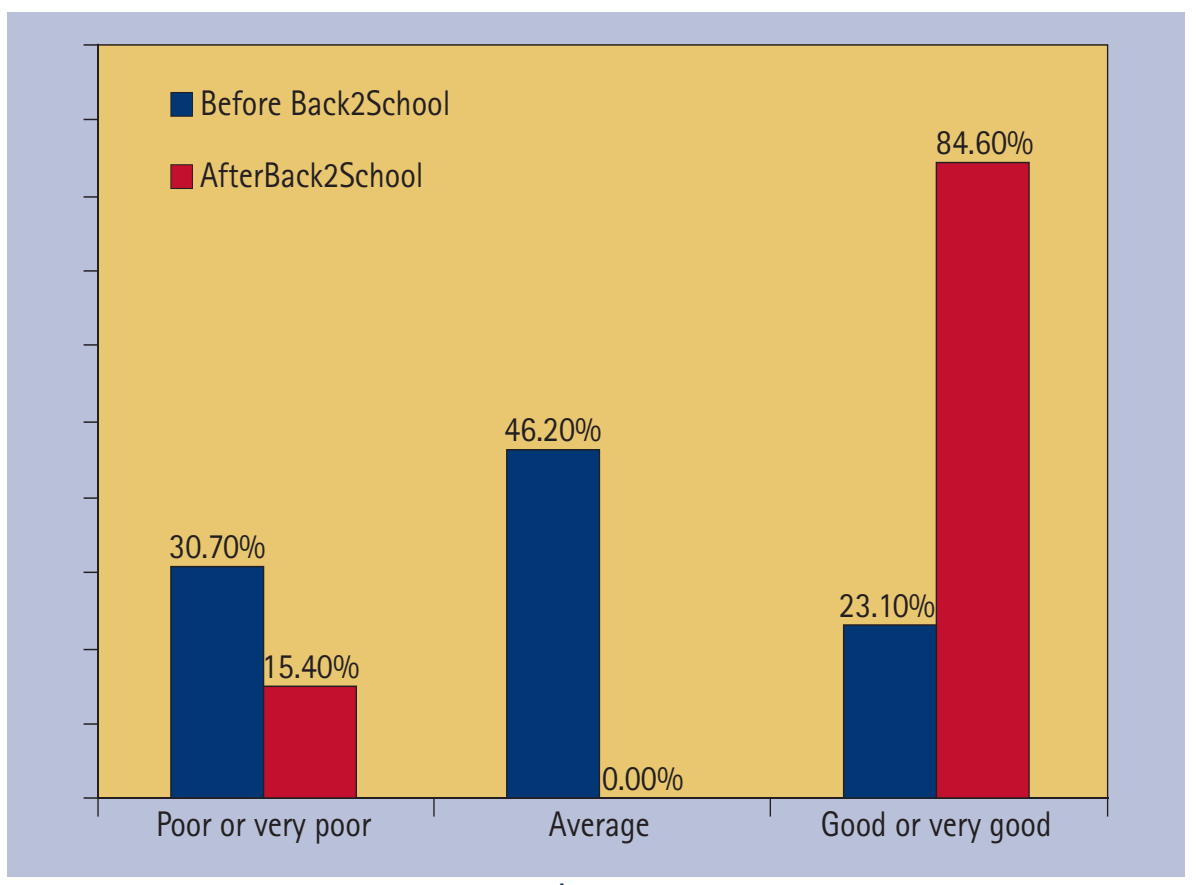

Fig. 1 Impact of programme on how parents/carers would rate the health of their child's mouth

the letters about their children's treatment needs and although this correspondence included the CDS contact numbers only one parent had telephoned the service before this programme and only $6 \%$ of the children been taken to a GDP. This identified the crucial role of language and cultural support in the success of the project and the need to address these barriers to care. The outreach team contacting the families both took time to answer questions raised by the families and communicated with parents that were unable to speak English in their own language. However, 13 families still refused appointments or discussion about oral health of their children and 16 (22\%) target children and siblings were not brought to appointments that their families had made for them and had confirmed they would attend. These were children of parents who had positively consented to the fluoride application programme in the school and it was felt that they would be more engaged with receiving treatment for their child. It suggests that a lot more work needs to be done to overcome the barriers for these children if they are to avoid DN. As Newton suggests ${ }^{16}$ 'dental neglect' is an emotive topic and the accusation of neglect carries with it pejorative implications for parents and carers. Thus the CDS is working closely with the schools, families and safeguarding teams to investigate ways to address this, rather than alienate the very people we are to try assist.

The families' feedback on the MDU was very positive with $92 \%$ of those asked saying they were happy and found the location convenient. Eighty-five percent now felt they would take their child to a GDP. One parent was still unhappy as they were awaiting a general anaesthesia appointment and one parent felt the appointment was too rushed. The impact score on how parents rated their child's oral health four weeks after the project suggested a positive outcome perceived by the families from receiving dental treatment for their child (Fig. 1); however results should be interpreted with caution due to small sample size.

The decision to provide healthcare with a mobile clinic is one which health and educational services are increasingly pursuing. In the US ${ }^{17}$ a school-based MDU demonstrated improved access to dental care at a smaller cost for low-income children compared to fixed site clinics. The following factors were identified as being important for success: sustained funding, experienced operational managers, strong relationships with school staff, and resources directed at maximising consent form returns. In the UK, MDU have been used to significantly increase the uptake of dental care following school screenings ${ }^{18}$ and have been very successful in providing dental care for homeless people. ${ }^{19}$ Mobile health units (MHU) have improved access 
to healthcare among Mexican immigrants in northern Colorado. ${ }^{20}$ Referral to a fixed site clinic following general health screening proved an effective tool to uncover medical and mental illness and to instigate treatment. They concluded that this was an important first step in eliminating health disparities among this population. A review of literature on MHU for the International Red Cross ${ }^{21}$ identified a number of key messages relevant to nonemergency service provision:

- The main objective is to improve access of targeted population groups to the health system

- MHUs should be run on a temporary basis, before the opening (or reopening) of permanent health facilities, or to refer isolated population groups to existing facilities

- Importance of a fixed site clinic on which the MHU can depend

- High cost of services, but those with the highest rates of efficiency are those treating pathologies in a single visit, such as dental problems

- Importance of community involvement

- To encourage attendance, first offer services, which are of the greatest interest to the population.

The Back2school pilot fits this Red Cross model; a short programme with community involvement, carefully targeted with fixed site CDS and GDP services for follow-up. The units of dental activity (UDA) achieved were 95.2, which at a GDP rate of payment of $£ 20-£ 30$ per UDA would be an income of $£ 1,904-£ 2,856$. The MDU costs (which include transportation of the mobile, petrol, permits, maintenance, cleaning, operation support, dental consumables, overheads, office support costs and decontamination costs) are currently £370 a session, with staff costs of £218.67. This is a total cost of $£ 5,886.70$ for the ten sessions, which means the UDA's value would need to be set at $£ 61.84$. This cost is high, but is feasible for a short programme, using existing resources that could be repeated and has the potential to avert the high cost and emotional impact of dental treatment under general anaesthesia for a young child. Currently dental treatment is the fourth most common reason why a child is admitted to hospital in England ${ }^{22}$ and the costs associated must be considerably greater than this UDA value. To make the service more cost effective the sessions could be extended, maybe working from 8.00 am until $7.00 \mathrm{pm}$, but families may not want to access care at these times. The Saturday service was very busy with no failed appointments and suggests that this day of the week may be easier for these families.

Changes to the wider National Health Service in England are driving a redesign of how oral healthcare will be delivered in the future. In addition to the development of a new NHS GDP contract, reconfiguration and rationalisation of services for those patients whose needs fall beyond the remit of the GDP is also being revised. ${ }^{23}$ The Steele report ${ }^{24}$ emphasised the need to focus on improved oral health as the outcome for NHS dental services and current changes offer a great opportunity to make this aspiration a reality for the children of England. Fayle ${ }^{23}$ recommends that to meet current challenges we need to carefully consider how best to design an integrated network of services with an appropriate range of skills and services to most effectively meet children's oral health needs and service design should aim to facilitate easy access for those children who may have highest need. In TH it seems that the challenge is getting the children that have an oral health need to access services. Barriers of cost do not apply as child treatment is free. Additionally, in this programme an oral health treatment need had been identified and families had been informed on two separate occasions. The MDU was sited in locations adjacent to the schools, with families contacted and reminded by telephone and yet barriers still remained. This pilot also involved very small numbers, a total of 180 target children's record cards were audited. Further research could address barriers for non-responders, larger numbers, different communities, longer MDU opening hours, weekend opening, direct access to DCPs and working closely with schools and other health and social family services.

\section{CONCLUSION}

One of the obstacles to identifying children at risk of DN is the traditional model of dental health provision, in which families must organise themselves and attend dental surgeries. In contrast to this, working closely with schools to identify children at risk of dental disease by screening, parent/carer information sessions, feedback to schools and fluoride varnish application and then developing services to identify and remove barriers to care, such as the use of a strategically placed MDU, could provide an alternative interdisciplinary and holistic approach to the problem of DN. This pilot demonstrates that the use of a community-based MDU has the potential to remove barriers to dental care access, both for the treatment of vulnerable children and as a first point of contact in the dental care pathway. Furthermore, a MDU can be a cost effective means of providing dental care. However, the careful planning of such services is vital to their success and must include the consideration of adequate funding, appropriate staffing, operational management, networks within the local community, stakeholder views and target population cultural and language issues. This pilot highlighted that if all vulnerable children are to be reached a lot more work needs to be done.

The authors would like to acknowledge Dr Ursula Bennett and Tricia Wallace for their vision and commitment in establishing the Happy Teeth programme. They would also like to thank $\mathrm{Dr}$ Grammati Sarri for her comments on this paper.

1. Tickle M, Milsom K M, Humphris $G M$, Blinkhorn A S Parental attitudes to the care of the carious primary dentition. Br Dent J 2003; 195: 451-455.

2. Watt R, Sheiham A. Health policy: Inequalities in oral health: a review of the evidence and recommendations for action. Br Dent J 1999; 187: 6-12.

3. Sheiham A. Dental caries affects body weight, growth and quality of life in pre-school children. Br Dent J 2006: 201: 625-626.

4. Harris J C, Balmer R C, Sidebotham P D. British Society of Paediatric Dentistry: a policy document on dental neglect in children. Int J Paediatr Dent 2009; D0I:10.111/j. 1365X.2009.00996.x.

5. American Academy of Paediatric Dentistry. Guideline on adolescent oral healthcare. Paediatr Dent 2005-2006; 27: 72-79.

6. National Institute for Health and Care Excellence Clinical guideline 89: when to suspect child maltreatment. London: NICE, 2009. Online guidelines available at http://www.nice.org.uk/cg89 (accessed July 2013)

7. Finch H, Keegan J, Ward K, Sanyal Sen B. Barriers to the receipt of dental care: a qualitative study. London: Social and Community Planning Research, 1988.

8. British Dental Association. Oral health inequalities policy. London: British Dental Association, 2009.

9. Jones C M, Woods K, Taylor G O. Social deprivation and tooth decay in Scottish schoolchildren. Health Bull (Edinb) 1997; 55: 11-15.

10. French A D, Carmichael C L, Furness J A, Rugg-Gunn A J. The relationship between social class and dental health in 5-year-old children in the North and South of England. Br Dent J 1984; 156: 83-86.

11. Croucher R, Sohanpal R Improving access to dental care in East London's ethnic minority groups: community based qualitative study. Community 
Dent Health 2006; 23: 95-100.

12. Fox $C$. Evidence summary: what is the effectiveness of alternative approaches for increasing dental attendance by poor families or families from deprived areas? Br Dent J 2010; 208: 167-171

13. Sarri G, Marcenes W. Child dental neglect: is it a neglected area in the UK? Br Dent J 2012 213: 103-104.

14. Public Health England. Results of five year old children survey, 2007/08. Public Health England, 2009. Online article available at http://www. nwph.net/dentalhealth/survey-results.aspx?id=1 (accessed July 2013).

15. London Borough of Tower Hamlets Joint Strategic Needs Assessment. An overview of health and wellbeing in Tower Hamlets: child poverty needs assessment 2010/11. London: Tower Hamlets Primary Care Trust, 2011.
16. Newton J T. Summary of: A school-based epidemiological study of dental neglect among adolescents in a deprived area of the UK. Br Dent $J$ 2012; 213: 512

17. Jackson D M, Jahnke L R, Kerber L, Nyer $G$, Siemens K, Clark C. Creating a successful school-based mobile dental programme. J Sch Health 2007; 77: 1-6.

18. Clarke J R, Bradnock G, Hamburger R. The uptake and completion of dental treatment using a mobile clinic in central Birmingham UK. Community Dent Health 1992; 9: 181-185.

19. Simons D, Pearson N, Movasaghi Z. Developing dental services for homeless people in East London. Br Dent J 2012; 213: 360

20. Daiz-Perez M J, Farley T, Cabanis C M. A programme to improve access to health care among Mexican immigrants in rural Colorado. J Rural Health 2004;
20: 258-264.

21. International Committee of the Red Cross. Mobile health units: methodological approach. Geneva: ICRC, 2006. Online article available at http://www. icrc.org/eng/assets/files/other/icrc_002_0886.pdf (accessed August 2013).

22. Hansard. Written answers. Hospitals: admissions (Parliamentary debates 16 April 2012). Report 543: 116W. London: House of Commons Official Report 2012. Online debates available at http://www. publications.parliament.uk/pa/cm201212/cmhansrd/ chan288.pdf (accessed August 2013).

23. Fayle S. Improving oral healthcare for children - a great opportunity. Br Dent J 2013; 214: 547-549.

24. Steele J, Clarke J, Wilson T, Rooney E. NHS dental services in England: an independent review led by Professor Jimmy Steele. London: Department of Health, 2009. 